\title{
Maturation of Speech-Sound ERPs in 5-6-Year-Old Children: A Longitudinal Study
}

\author{
Tanja Linnavalli1,2*, Vesa Putkinen ${ }^{1,3}$, Minna Huotilainen ${ }^{1,2}$ and Mari Tervaniemi ${ }^{1,2}$ \\ ${ }^{1}$ Cognitive Brain Research Unit, Faculty of Medicine, University of Helsinki, Helsinki, Finland, ${ }^{2}$ Cicero Learning, Faculty \\ of Educational Sciences, University of Helsinki, Helsinki, Finland, ${ }^{3}$ Turku PET Centre, University of Turku, Turku, Finland
}

\section{OPEN ACCESS}

Edited by:

Josef P. Rauschecker, Georgetown University, United States

Reviewed by:

Erich Schröger,

Leipzig University, Germany

Dan Zhang,

Tsinghua University, China

${ }^{*}$ Correspondence:

Tanja Linnavalli

tanja.linnavalli@helsinki.fi

Specialty section:

This article was submitted to Auditory Cognitive Neuroscience,

a section of the journal

Frontiers in Neuroscience

Received: 26 July 2018 Accepted: 19 October 2018 Published: 06 November 2018

Citation:

Linnavalli T, Putkinen V, Huotilainen $M$ and Tervaniemi M (2018) Maturation of Speech-Sound ERPs in 5-6-Year-Old Children:

A Longitudinal Study.

Front. Neurosci. 12:814. doi: 10.3389/fnins.2018.00814
The maturation of 5-6-year-old children's auditory discrimination - indicated by the development of the auditory event-related-potentials (ERPS) - has not been previously studied in longitudinal settings. For the first time, we present here the results based on extensive dataset collected from 75 children. We followed the 5- to 6-year-olds for 20 months and measured their ERPs four times with the same multifeature paradigm with phonemic stimuli. The amplitude of the mismatch negativity (MMN) response increased during this time for vowel, vowel duration and frequency changes. Furthermore, the P3a component started to mature toward adult-like positivity for the vowel, intensity and frequency deviants and the late discriminative negativity (LDN) component decreased with age for vowel and intensity deviants. All the changes in the components seemed to happen during the second follow-up year, when Finnish children are taught letter symbols and other preliminary academic skills before going to school at the age of seven. Therefore, further studies are needed to clarify if these changes in the auditory discrimination are purely age-related or due to increasing linguistic knowledge of the children.

Keywords: MMN, P3a, LDN, speech, children, maturation

\section{INTRODUCTION}

Auditory event-related responses are an important tool to investigate auditory cognition and its development beyond behavioral measures. However, the maturation of auditory event-related responses in children is a field not well covered by the present literature. Some components - such as mismatch negativity (MMN) - are known to be evident already in new-born babies, while our knowledge of the emergence of others [e.g., P3a and late discriminative negativity (LDN)] is scarce and even contradictory. The present knowledge on components elicited by changes in the sound stream, namely MMN, P3a and LDN, is briefly presented below.

The mismatch negativity (MMN) is a component of event-related responses that is thought to reflect the neural discrimination of change in the stream of repeating stimuli (Näätänen, 1992) or a mismatch between the predicted and perceived acoustic input (Winkler et al., 2009). Apparently, in adults the MMN is of negative polarity and it is thought to originate from two main areas, namely prefrontal cortex and the supratemporal planes of the auditory cortices (Näätänen and Escera, 2000; Rinne et al., 2000).

The MMN is a very convenient tool for studying children, as it does not require concentration in task to be elicited (Näätänen et al., 2010; for a review, see e.g., Näätänen et al., 2007). Regarding 
developmental studies, it is noteworthy that already fetuses (Huotilainen et al., 2005) and newborn babies show MMN-like responses (Cheour et al., 2000; Trainor et al., 2001; Kushnerenko et al., 2002b; Partanen et al., 2013a) for e.g., frequency changes (Alho et al., 1990), speech stimuli (Csépe, 1995), musical stimuli (Partanen et al., 2013a) and emotional pseudo-word stimuli (Kostilainen et al., 2018). Likewise, the MMN is well established in pre-schoolers (Lovio et al., 2009; Lee et al., 2012) and in schoolchildren (Kraus et al., 1999; Cheour et al., 2000; Datta et al., 2010). Yet, with subtle acoustic changes, MMN amplitudes are reported to be small during preschool and early school-age (Lovio et al., 2009; see e.g., Cheour, et al., 2000). The MMN or its early counterpart mismatch response (MMR) have been recorded in 3-12-year-old children for changes in frequency (Shafer et al., 2000; Maurer et al., 2003), intensity (Lovio et al., 2009; Lovio et al., 2010; Partanen et al., 2013c), phonemes (Kraus et al., 1999; Čeponienè et al., 2004; Lovio et al., 2009, 2010; Datta et al., 2010; Kuuluvainen et al., 2016), and vowel duration (Lovio et al., 2009, 2010). Furthermore, the MMN has been recorded in children for more abstract features, such as changes of direction of frequency change in pairs of sounds (Gumenyuk et al., 2003).

The maturation of MMN responses has been studied predominantly with cross-sectional studies. Shafer et al. (2010) did not find any difference in magnitude of the MMN amplitude between 4-5-year-old and 6-7-year-old children's responses to vowel changes, suggesting that the amplitude does not increase during these years. In another study, Shafer et al. (2000) compared the responses for frequency changes in children and adults. There was no difference in the MMN amplitudes between the four age groups (4-year-olds, 5-6-year-olds, 7-8-year-olds, and 9-10-year-olds), or between children and adults. Gomot et al. (2000) studied the maturation of MMN components by comparing 5-7-year-old children's, 8-10-year-old children's and adults' responses to frequency changes. In line with Shafer et al. (2000, 2010), there were no statistically significant differences in mean amplitudes of frontal MMN between any of the three groups.

Inconsistent with these studies, Lee et al. (2012) compared 4-, 5- and 6-year-old children, and found that small vowel deviances elicited adult-like MMN responses only in the oldest child group. For small and large lexical tone changes and large vowel changes, the MMN amplitudes were similar in all age groups. Furthermore, Bishop et al. (2011) compared 7-12-year-old children to 13-16-year-old teenagers and adults. The responses for frequency and phoneme changes revealed that the MMN amplitude increased with age. Additionally, Lovio et al. (2009) studied MMN responses of 6-7-year-old children for vowel, vowel duration, consonant, frequency and intensity change. The children's MMN amplitudes were smaller than those observed in adults in a study by Pakarinen et al. (2009) that used the same multifeature paradigm. Partanen et al. (2013c) studied 4-6-year-old pre-schoolers' and 7-12-year-old schoolchildren's MMN responses to changes in vowel duration, frequency, gap, intensity and vowel identity, and found that only the older children showed MMN responses to vowel change. However, only the younger children showed MMNs to frequency deviants.
Based on the literature, it is difficult to summarize the maturation of MMN responses: Shafer et al. (2000, 2010) and Gomot et al. (2000) did not find any evidence for age-related differences in the magnitude of MMN, while other studies did (Bishop et al., 2011; Liu et al., 2014; also compare Lovio et al., 2009 vs. Pakarinen et al., 2009). The discrepant results might result from methodological differences across these studies: the paradigms are different, the saliency of changes in different deviant types (e.g., vowel change vs. consonant change) is not comparable, the age-groups might be composed of children from different developmental stages and the number of participants is mostly small, considering the amount of variance that children's responses typically represent.

In adults studied in a passive condition, the MMN is sometimes followed by a fronto-centrally maximal positive peak with latency around $300 \mathrm{~ms}$ referred to as the $\mathrm{P} 3 \mathrm{a}$ response. The P3a is thought to reflect orienting of attention (Escera et al., 1998; Friedman et al., 2001; Berti et al., 2004; Polich, 2007), and very salient or novel distractors elicit larger P3a components than more subtle ones (Escera et al., 1998; Yago et al., 2001; Berti et al., 2004). Already infants show a positive component to large deviants, similar to the adult P3a (Kushnerenko et al., 2002a; Kushnerenko et al., 2007; Háden et al., 2009). Putkinen et al. (2012) found a P3a in 2-year-old children in response to salient deviants, such as large frequency and duration changes, soundsource location deviants and novel sounds. Wetzel et al. (2006) compared the P3a responses of adults, 6-8- and 10-12-year-old children in a passive condition, and found that unlike adults, both child groups showed P3a responses to frequency deviation with younger group showing larger responses. Furthermore, Gumenyuk et al. (2004) found some age-related differences in P3a amplitudes while comparing 8-9-, 10-11- and 12-13-yearold children. The P3a response for novel sounds was significantly smaller in the oldest child group than in the younger groups that did not differ from each other. However, as Kihara et al. (2010) studied 4 to 12-year-old children, they found that P3a responses to novel sounds were larger in older children. Additionally, some studies have not found any age-related differences in P3a responses (Ruhnau et al., 2010, 2013). As the scarcity of the literature reveals, more research is needed on P3a and its maturation.

The LDN (Korpilahti et al., 1995), is a fronto-central negative response occurring typically 350-550 $\mathrm{ms}$ after stimulus onset, although it has been reported in later latency ranges (Putkinen et al., 2012; Ervast et al., 2015). As the LDN seems to have distinct neural generators from those of the MMN (Čeponienè et al., 2004; Hommet et al., 2009), it should not be regarded as a late manifestation of the MMN. The functional significance of LDN response is not clear: some studies have reported it to be more pronounced for speech than non-speech sounds (Korpilahti et al., 1996, 2001; Bishop et al., 2011; Kuuluvainen et al., 2016), whereas others have not found any such effect (Čeponienè et al., 2002; Putkinen et al., 2012).

The LDN response has been recorded mainly in pre-school (Korpilahti et al., 1995, 2001; Ceponiene et al., 2003; Maurer et al., 2003) and school-age children (Korpilahti et al., 1995; Čeponienè et al., 1998, Cheour et al., 2001; Čeponienè et al., 2002; 
Shafer et al., 2005; Hommet et al., 2009; Datta et al., 2010; Bishop et al., 2011; Liu et al., 2014). It has been reported to be nearly absent in adults (Liu et al., 2014). For instance, Gumenyuk et al. (2004), compared small groups of 8-9-, 1011 - and 12-13-year-old children and found that the youngest group had larger LDN amplitudes to novel sounds than the older groups which did not differ from each other. In line with this, Bishop et al. (2011) studied groups of 7-12-year-old children, 13-16-year-old adolescents, and adults, and found that LDN responses to phoneme deviation decreased with age. Furthermore, Hommet et al. (2009) compared the responses of 8-10-year-old children and 14-23-year-old adolescents and young adults with developmental dyslexia to those of matched peer groups without dyslexia. In typically developing participants, the younger group showed larger LDN amplitudes to consonant change. However, no such difference was found in dyslexic participants.

There is also evidence that does not support the suggestion of LDN magnitude decreasing with age. In a study comparing 3-4-year-old children, 8-9-year-old children and adults, Liu et al. (2014) found that even though both child groups showed late negativity for lexical tone change not seen in the adults, the older children showed the largest LDN responses for consonant contrasts. In addition, Hong et al. (2018) compared 6-yearold poor and typical readers and found that LDN responses for consonant changes were smaller in poor readers' group, suggesting that larger LDN indicates more mature responses.

To summarize, we do not know how LDN matures over the childhood years, and whether its magnitude actually depends on the stimulus type.

Our aim was to monitor the maturation of auditory changerelated responses, MMN, P3a and LDN in pre-school children. As low socio-economic status (SES) is known to have an association with brain activity (Tomalski et al., 2013) and reduced language and literacy skills (see e.g., Lipina and Posner, 2012), we also wanted to see whether socio-economic background of the children - represented here by maternal education level - affects the studied maturation.

The study is part of a larger project investigating children's neural speech-sound processing and linguistic development (Linnavalli et al., 2017, 2018). The 5-6-year-olds were chosen as participants because this age-group has not been previously studied in longitudinal settings with auditory ERPs. In addition, children in Finland are given tuition in some academic skills (like recognizing the alphabet and numbers) at the age of 5-6 years in order to get them prepared to enter primary school and thus, this is a very important period for the development of linguistic skills. So, investigating their neurocognitive development is of great importance in order to know e.g., about the progress in children's perceptual and cognitive processes in audition.

To our knowledge, this is the first study following a considerable number (75) of 5-6-year-olds for nearly 2 years. The children were measured four times with the same paradigm including phonemic changes. This experimental paradigm allows us to make strong conclusions of the maturation of children's responses before school-age.

\section{MATERIALS AND METHODS}

\section{Participants}

Originally 84 children were recruited from 14 municipal kindergartens to participate in the study. Five children dropped out from the EEG study after the first measurement and two were excluded because of developmental problems. Furthermore, two were excluded due to too noisy data in more than two measurements. Thus, 75 children were included in the study [mean age in the first measurements being 63 months (SD 3.2), in the second measurements 70 months (3.1), in the third 77 (3.1) and in the fourth 83 (3.2)]. The children attended municipal kindergartens in Helsinki metropolitan area, and 62 of them were native Finnish speakers. Thirteen were bilinguals having some other language than Finnish as their native language but attending Finnish-language kindergartens. The mean for mother's education was $4.8(1.5)$ on a scale from $1-7$, where 5 stands for lower university/bachelor's degree.

The guardians signed a written informed consent and the children were asked for their verbal assent before each experiment. The experiment protocol was approved by The Review Board of the Humanities and Social and Behavioral Sciences in the University of Helsinki, Finland.

\section{The ERP Paradigm}

The stimuli were made with semisynthetic Speech Generation Method (for details, see Alku et al., 1999). In order to collect a large amount of data in a short time - essential when measuring children - we used the multifeature paradigm (Figure 1) (Näätänen et al., 2004). In the multifeature paradigm, every other stimulus is a standard and every other a deviant, and several different deviant types alternate so that each deviant type differs from the standard in only one feature (e.g., in frequency or duration). Thus, even though the deviants occur in $50 \%$ of the sounds, each deviant type appears only in e.g., $10 \%$ of the trials. MMN responses of healthy adults and children in the multifeature paradigm have been shown to be comparable to those elicited by traditional oddball paradigm (Kujala et al., 2006; Pakarinen et al., 2009; Partanen et al., 2013b,c).

The standard stimuli STD $(P=0.50)$ were either /pi:/ or /te:/, presented in separate blocks (Table 1). As deviating stimuli, the paradigm included vowel change $\operatorname{VOW}(P=0.10)$, vowel duration change DUR $(P=0.10)$, consonant change CON $(P=0.10)$, intensity change INT (louder $P=0.05$ and softer $P=0.05$ ) and frequency change FRE (higher $P=0.05$, lower $P=0.05)$. The duration of all stimuli was $170 \mathrm{~ms}$, excluding

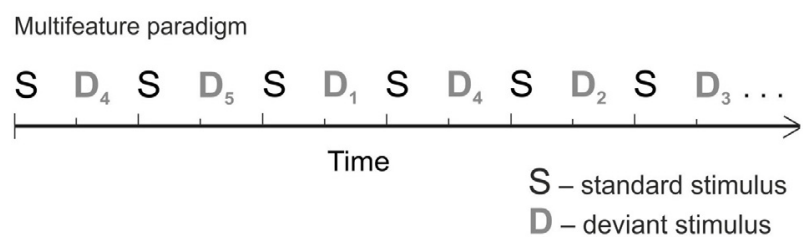

FIGURE 1 | The multifeature paradigm 
TABLE 1 | The stimuli of the multifeature paradigm.

\begin{tabular}{lcccccc}
\hline Block & STD & VOW & DUR & CON & INT & FRE \\
\hline $1 \& 2$ & /te:/ & /ti:/ & /te/ & $/$ pe:/ & $\pm 7 \mathrm{~dB}$ & $\pm 8 \%$ \\
$3 \& 4$ & /pi:/ & /pe:/ & /pi/ & /ti:/ & $\pm 7 \mathrm{~dB}$ & $\pm 8 \%$ \\
\hline
\end{tabular}

Four blocks (two blocks for each standard stimuli) were played for the participants. The blocks were played in randomized order.

vowel duration change DUR (100 ms). Stimulus onsets were $500 \mathrm{~ms}$ apart from each other. F0 was $101 \mathrm{~Hz}$, excluding the frequency change FRE which had the f0s of either 93 or $109 \mathrm{~Hz}$. Intensity of the stimuli was $\sim 70 \mathrm{~dB}$ (SPL), and the intensity change INT had intensities of either 63 or $77 \mathrm{~dB}$. There were 465 stimuli in each of the four blocks that were counterbalanced. Each block lasted for about $5 \mathrm{~min}$ and the total EEG recording net time was $20 \mathrm{~min}$. Only the participants with four accepted blocks from the measurement were included in the analyses. The identical experiment paradigm has been used in measuring MMN responses in adults (Pakarinen et al., 2009) and children (Lovio et al., 2009; Linnavalli et al., 2017).

\section{The Procedure}

All the EEG measurements were conducted during the children's normal daily stay at kindergarten in the kindergarten premises, in separate rooms with only the participant and the experimenter(s) present. During the measurement, the children watched a muted children's movie, and were asked to avoid unnecessary movement, to ignore the experimental stimuli, and to concentrate on the movie. The stimuli were presented via Sony Professional MDR-7506 headphones. Cookies and soft drinks were offered during the short breaks between blocks. With preparation, one measurement took approximately an hour.

\section{Data Recording and Processing}

The experimental paradigm was implemented with Presentation 17.0 (Neurobehavioral Systems, Inc., Albany, CA, United States). The EEG was recorded with $32 \mathrm{Ag}$-AgCl scalp electrodes according to international 10-20 system by using ActiCap (Brain Products, Germany). The EEG equipment was portable (Brainvision QuickAmp amplifier). The EEG data were registered with sample rate of $500 \mathrm{~Hz}$. Recording reference was the average signal of all electrodes. Two additional active electrodes were placed on the mastoid bones.

EEG was processed with BESA 5.3. software (MEGIS Software $\mathrm{GmbH}$, Gräfelfing, Germany). We interpolated noisy electrodes and removed eye blink artifacts using semi-automatic Besa PCA method. The percentage of accepted trials averaged over all participants and the number of interpolated channels averaged over all blocks for each measurement are listed in Table 2. Frequencies under $0.5 \mathrm{~Hz}$ and over $30 \mathrm{~Hz}$ were filtered out offline and we re-referenced the data to the mean of the mastoids. Inspected epochs were extracted from EEG from $-100 \mathrm{~ms}$ before onset to $500 \mathrm{~ms}$ after the onset of the stimuli. EEG-epochs with amplitudes exceeding $\pm 120 \mu \mathrm{V}$ were excluded from the analyses. The responses were averaged for each participant and the averaged responses were then
TABLE 2 | The percentage of accepted trials and the number of interpolated channels.

\begin{tabular}{|c|c|c|c|c|}
\hline & \multicolumn{4}{|c|}{ Measurements } \\
\hline & 1st $(N=74)$ & 2nd $(N=66)$ & $\operatorname{3rd}(N=61)$ & 4th $(N=65)$ \\
\hline \multicolumn{5}{|c|}{ Accepted trials (percentage) } \\
\hline mean (SD) & $93.3(5.9)$ & $93.6(5.3)$ & $92.7(6.1)$ & $95.0(4.6)$ \\
\hline $\max$ & 99.3 & 99.2 & 99.2 & 99.3 \\
\hline $\min$ & 67.0 & 67.1 & 69.0 & 66.5 \\
\hline median & 94.8 & 95.5 & 93.8 & 96.1 \\
\hline \multicolumn{5}{|c|}{ Interpolated channels (number) } \\
\hline \multicolumn{5}{|c|}{ Out of 32 channels } \\
\hline mean (SD) & $2.0(1.5)$ & $2.4(1.8)$ & $2.2(1.4)$ & $2.1(1.4)$ \\
\hline $\max$ & 7 & 8 & 8 & 7 \\
\hline $\min$ & 0 & 0 & 0 & 0 \\
\hline median & 1 & 2 & 2 & 2 \\
\hline \multicolumn{5}{|c|}{ Out of 9 channels } \\
\hline mean (SD) & $0.69(0.71)$ & $0.72(0.71)$ & $0.59(0.65)$ & $0.43(0.58)$ \\
\hline $\max$ & 3 & 3 & 3 & 3 \\
\hline $\min$ & 0 & 0 & 0 & 0 \\
\hline median & 1 & 1 & 1 & 0 \\
\hline
\end{tabular}

The accepted trials are averaged over all participants and interpolated channels over all blocks (4 blocks per a participant) for each measurement. The interpolated channels are reported for both all 32 channels used in the measurements and for 9 channels (F3, Fz, F4, C3, Cz, C4, P3, Pz, and P4) used in the analyses.

exported to MATLAB R2017 (The MathWorks Inc., Natick, MA, United States).

For the intensity deviant, we averaged together the responses to both intensity changes (louder and softer) and similarly, for the frequency deviant response we averaged together the responses to increments and decrements of frequency. The standard and deviant trials from all four blocks were combined according to their stimulus category. The subtraction signals were created for each deviant stimulus by subtracting the participant's average standard response from the average deviant responses, separately for each participant, each deviant, and each electrode. Typically for MMN paradigms, we inspected further the electrodes F3, Fz, F4, C3, Cz, C4, P3, Pz and $\mathrm{P} 4$, as this reveals front-back and left-right distribution of the brain responses. Mean amplitudes were calculated separately for each deviant and each measurement for MMN, LDN and P3a responses over $50 \mathrm{~ms}$ time window. The time windows were chosen based on visual inspection supported by data from previous studies showing children's MMN, LDN and P3a responses.

\section{Statistical Analyses}

Several children either did not participate in all four measurements or showed noisy data that had to be rejected, on some measurement points. Thus, the number of participants varied in the measurements, being 74 in the first, 66 in the second, 61 in the third and 65 in the fourth measurement. Therefore, we conducted the analyses with linear mixed models, more specifically, with linear growth curve model (West, 2009) that allows the analysis of longitudinal data with different number of data points per subject. In addition, with linear 
growth curve model it is possible to take into account the individual ages of each participant during each measurement. The analyses were run separately for all inspected responses. Centered values for age (months) and mother's education (scale from 1-7), along with all the interaction between these, acted as predictors and averaged responses as dependent variables. For $\mathrm{MMN}$ and $\mathrm{P} 3 \mathrm{a}$, we averaged the responses for each deviant over the frontline electrodes (F4, Fz, and F3) and for LDN we averaged the responses for each deviant over all the nine electrodes (F4, Fz, F3, C3, Cz, C4, P3, Pz, and P4).

We used random intercept model in all analyses and chose compound symmetry as the covariance structure on the basis of Schwarz's Bayesian Criterion (BIC). We conducted the analyses with SPSS 24 (IBM Corporation, NY, United States) and set the alpha level at $p<0.05$.

\section{RESULTS}

All the averaged MMN and LDN responses over chosen electrodes were significantly different from zero at the group level in the inspected time windows ( $p<0.001$, each). The P3a response was significantly different from zero at the group level in the inspected time windows ( $p<0.001$, each), excluding the vowel duration deviant in all of the four measurements $(p=0.665$, $p=0.256, p=0.764$ and $p=0.342$, respectively) and the frequency deviant in the fourth measurement $(p=0.055)$. Mean amplitudes and peak latencies defining the inspected time windows for each response, deviant and measurement are depicted in Tables 3, 4.

The amplitudes of the MMN responses for frequency, vowel duration and vowel deviants increased with age, whereas the

TABLE 3 | Mean MMN, P3a and LDN ( $\mu$ V) amplitudes for all four measurements.

\begin{tabular}{|c|c|c|c|c|}
\hline \multirow[b]{2}{*}{ Measurement } & \multicolumn{4}{|c|}{ Amplitude (SD) $\mu \mathrm{V}$} \\
\hline & 1st & 2nd & $3 r d$ & 4th \\
\hline \multicolumn{5}{|l|}{$M M N$} \\
\hline VOW & $-1.97(2.6)$ & $-2.58(2.6)$ & $-3.38(3.0)$ & $-2.89(2.8)$ \\
\hline DUR & $-3.65(2.4)$ & $-4.14(2.9)$ & $-4.83(3.1)$ & $-4.58(2.4)$ \\
\hline $\mathrm{CON}$ & $-2.32(2.2)$ & $-2.75(2.5)$ & $-2.78(2.5)$ & $-2.63(2.1)$ \\
\hline INT & $-2.62(2.4)$ & $-2.89(2.2)$ & $-2.26(2.5)$ & $-2.42(2.0)$ \\
\hline FRE & $-1.98(2.5)$ & $-2.56(2.6)$ & $-3.05(2.9)$ & $-2.63(2.8)$ \\
\hline \multicolumn{5}{|l|}{ P3а } \\
\hline VOW & $-4.37(2.6)$ & $-3.99(2.8)$ & $-3.44(2.9)$ & $-1.42(2.9)$ \\
\hline DUR & $-0.15(3.0)$ & $-0.32(2.3)$ & $-0.09(2.5)$ & $-0.22(1.9)$ \\
\hline CON & $-3.08(2.3)$ & $-3.27(2.6)$ & $-3.76(2.4)$ & $-3.19(2.3)$ \\
\hline INT & $-3.02(2.5)$ & $-3.56(2.4)$ & $-3.34(2.3)$ & $-2.27(2.0)$ \\
\hline FRE & $-2.51(2.2)$ & $-2.52(2.4)$ & $-2.04(2.6)$ & $-0.65(2.7)$ \\
\hline \multicolumn{5}{|l|}{$\angle D N$} \\
\hline VOW & $-5.63(2.7)$ & $-5.83(3.2)$ & $-6.08(2.8)$ & $-5.25(2.5)$ \\
\hline DUR & $-1.67(2.4)$ & $-1.76(2.2)$ & $-2.01(2.1)$ & $-1.70(1.9)$ \\
\hline CON & $-3.45(2.2)$ & $-3.64(2.4)$ & $-4.00(2.4)$ & $-3.04(2.2)$ \\
\hline INT & $-3.71(2.1)$ & $-3.93(2.4)$ & $-3.73(2.2)$ & $-2.94(2.2)$ \\
\hline FRE & $-3.86(2.3)$ & $-3.55(2.3)$ & $-4.35(2.1)$ & $-3.38(2.3)$ \\
\hline
\end{tabular}

Mean amplitudes for the MMN and the P3a are averaged over F3, Fz, and F4 electrodes and for the LDN over F3, FZ, F4, C3, CZ, C4, P3, Pz, and P4 electrodes.
TABLE 4 | The MMN, P3a and LDN peak latencies in milliseconds from the stimulus onset for each deviant in each measurement.

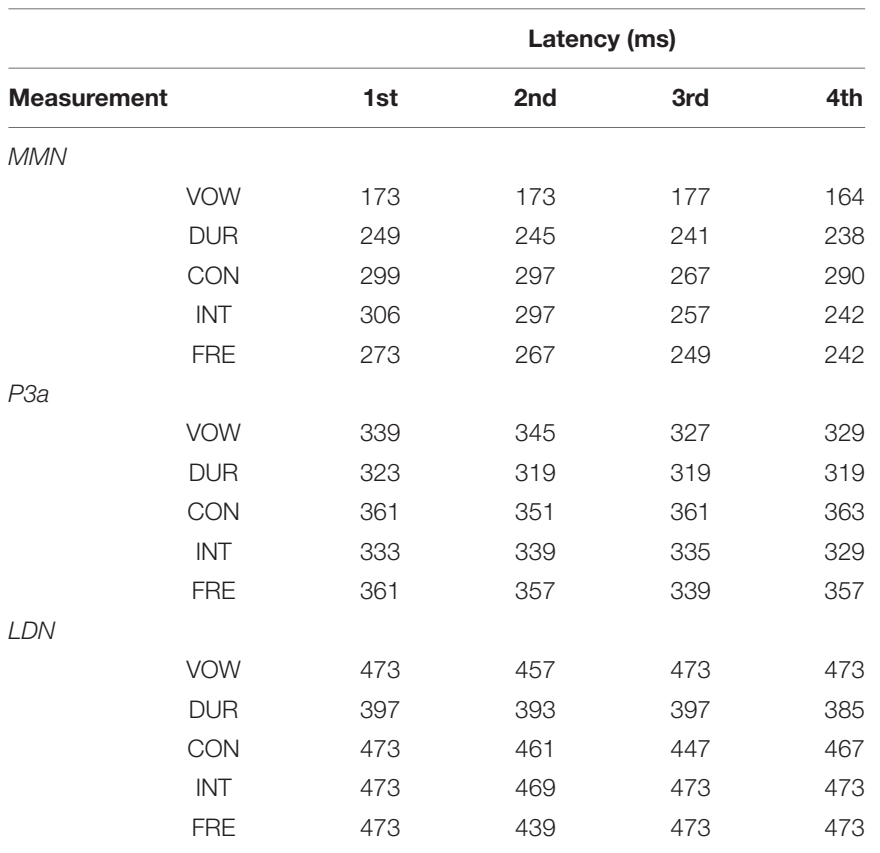

Please note that for the duration deviant, the change occurs at $100 \mathrm{~ms}$ after stimulus onset.

amplitudes decreased in the P3a time-window for frequency, vowel and intensity deviants. The amplitudes of the LDN responses for vowel and intensity deviants decreased by age during the follow-up. All the averaged standard responses are depicted in Figure 2 and all the subtraction signals for frontline electrodes are depicted in Figure 3. We report the significant or near significant main effects and interactions in the results. Additional tables covering all the results are in Supplementary Information.

Parameter estimates indicate how many microvolts the inspected responses change when variables with significant or marginally significant main effects or interactions increase one step (months for age and steps on a scale from 1 to 7 for mother's education).

\section{MMN}

The main effect of age was significant on the front line electrodes for vowel deviant $[F(1,191)=9.810, p=0.002$, parameter estimate -0.052988], duration deviant $[F(1,198)=11.337$, $p=0.001$, parameter estimate -0.059168$]$ and frequency deviant $[F(1,189)=5.285, p=0.023$, parameter estimate -0.034871$]$, showing an increase in MMN responses with age. All the results are depicted in Supplementary Table S1.

\section{P3a}

The main effect of age was significant on the front line electrodes for vowel deviant $[F(1,214)=46.864, p<0.001$, parameter estimate 0.140570$]$, intensity deviant $[F(1,210)=4.692$, $p=0.031$, parameter estimate 0.037629] and frequency deviant $[F(1,209)=24.889, p<0.001$, parameter estimate 0.089703], 


\section{Standard response}

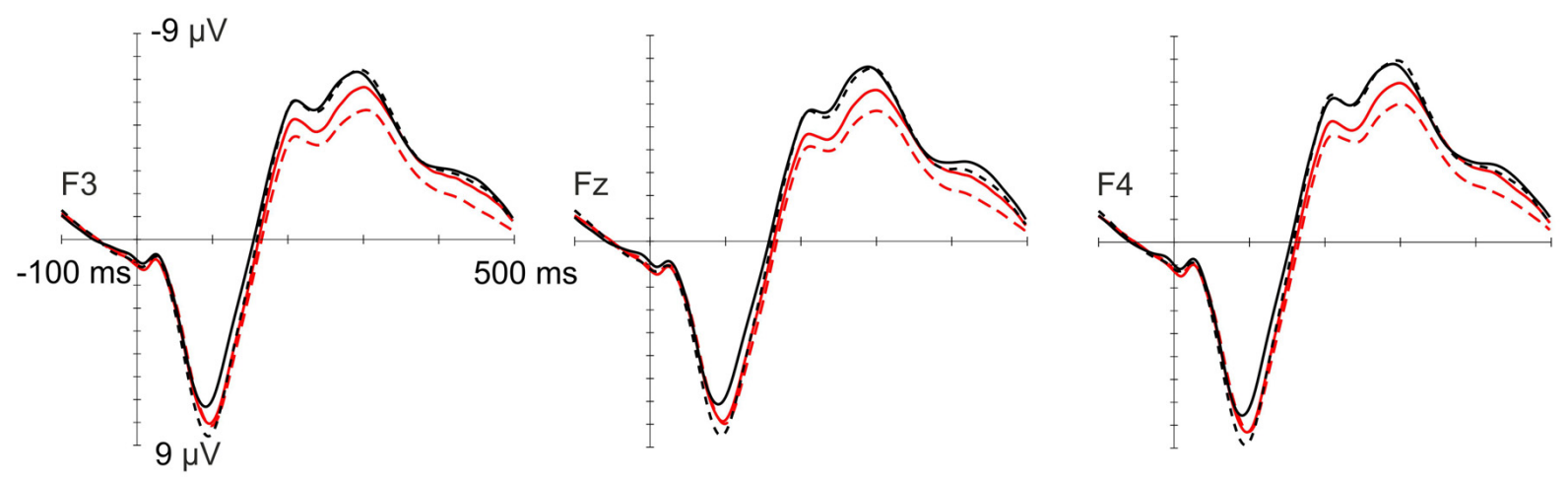

- - - 1st measurement __ 2nd measurement _ - - 3rd measurement _ $\quad$ 4th measurement

FIGURE 2 | Standard responses on frontline electrodes for all four measurements.

showing a decrease in amplitude in inspected time window. Furthermore, there was a significant interaction of mother's education and age for consonant deviant $[F(1,206)=3.937$, $p=0.049$, parameter estimate 0.022674] (Figure 4A) and a trend for the main effect of mother's education for consonant deviant $[F(1,66)=3.167, p=0.080$ parameter estimate 0.236972$]$ (Figure 4B), indicating that the P3a responses of children with higher maternal education were in average more mature and matured more with age than those of their peers with lower maternal education. All the results are depicted in Supplementary Table S2.

\section{LDN}

The main effect of age was significant on averaged deviants over nine electrodes for intensity deviant $[F(1,201)=8.220, p=0.005$, parameter estimate 0.042873] and marginally significant for vowel deviant $[F(1,195)=3.701, p=0.056$, parameter estimate 0.033238], showing a decrease in LDN responses with age. In addition, there was a significant interaction of age and mother's education for intensity $[F(1,201)=4.839, p=0.029$, parameter estimate 0.021813], indicating that higher mother's education further decreased the mean LDN amplitudes for intensity change (Figure 5A). Additionally, there was a trend for the interaction of age and mother's education for vowel deviant $[F(1,195)=2.922$, $p=0.089$, parameter estimate 0.019586], indicating that these responses decreased more with age in children with higher maternal education (Figure 5B). All the results are depicted in Supplementary Table S3.

\section{DISCUSSION}

To our knowledge, this is the first auditory ERP study reporting such a large number of children followed for nearly 2 years and measured four times with the paradigm including five deviants in parallel. In addition, instead of treating each measurement time as representative of mean age of children, our statistical analysis allowed us to take each individual measurement age into account, contributing to a model describing more accurately the development during the inspected 20 months.

\section{MMN}

Responses elicited by the vowel deviant, the vowel duration deviant and the frequency deviant increased clearly over the studied 20 months suggesting that at least during the 5th and 6th years of life, auditory change detection is still enhancing. Instead, there seems to be no signs of increase in MMN components for consonant and intensity deviants. The change in consonant deviant occurs within the first tens of milliseconds, and appears not to be very salient. Consistently with our results, a study in adults did not show any prominent MMN - not to mention P3a peaks in a similar paradigm used by Pakarinen et al. (2009). As for the intensity deviant, the mean MMN amplitudes are rather large compared with other deviants already in the beginning of the follow-up and this might explain why no increase was detected.

There is contradictory evidence regarding the increase or decrease of MMN amplitude with age and it is not known if MMN maturation has different phases along the childhood. According to our study, with 75 same-age participants, it seems that during the ages 5-6 years the pre-attentive auditory change detection for phoneme changes is still developing. What happens after this age-range, is not known and more longitudinal research is needed.

\section{P3a}

The stimulus changes in our study were acoustically small, and this probably explains why positive P3a was not apparent in any of the responses. However, the P3a responses elicited by the vowel deviant, intensity deviant and the frequency deviant changed over the studied 20 months. Thus, it seems that orienting of attention, which P3a is thought to reflect, is enhancing during the inspected 2 years for these sound features. 


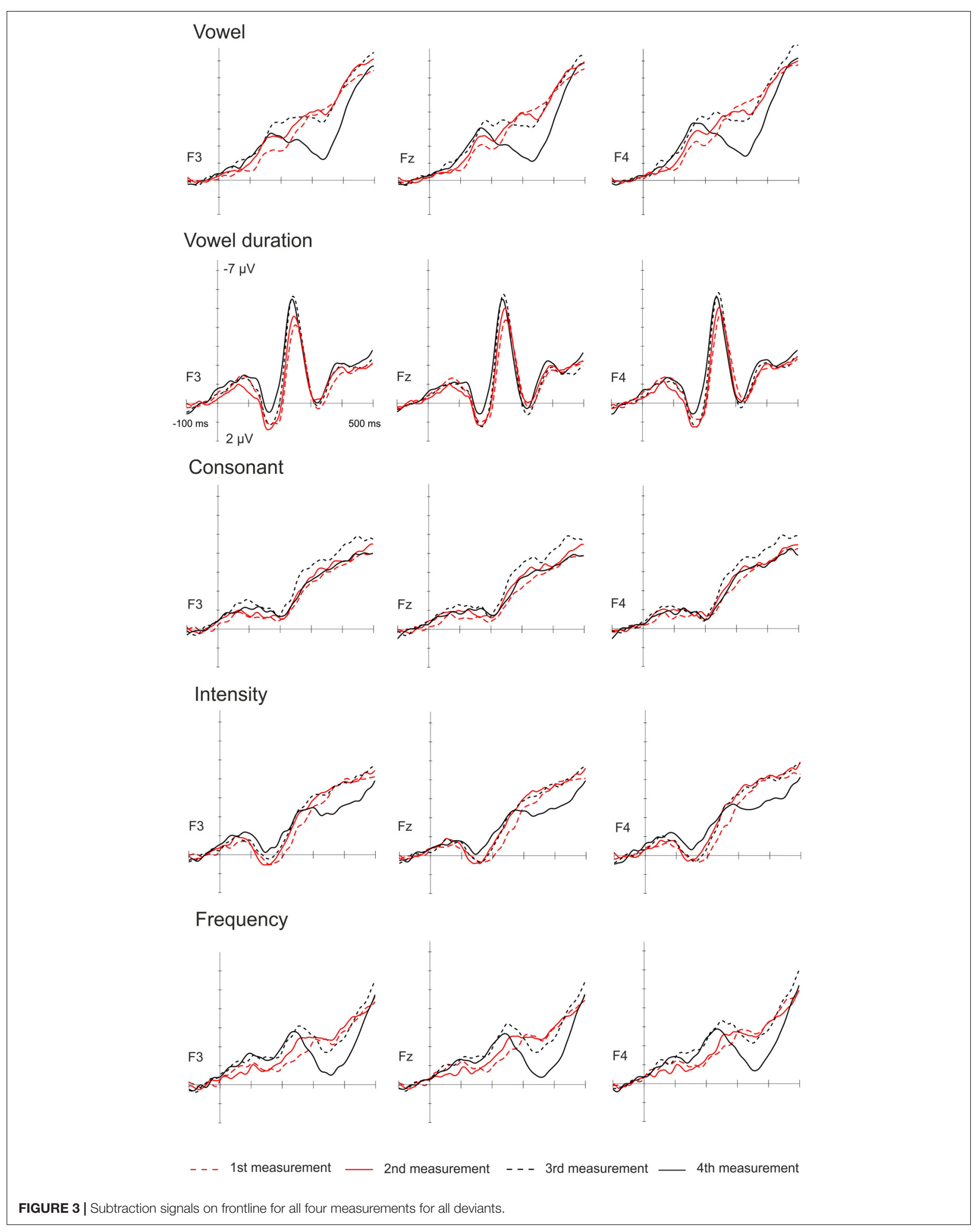




\section{P3a}

A

\section{Consonant}

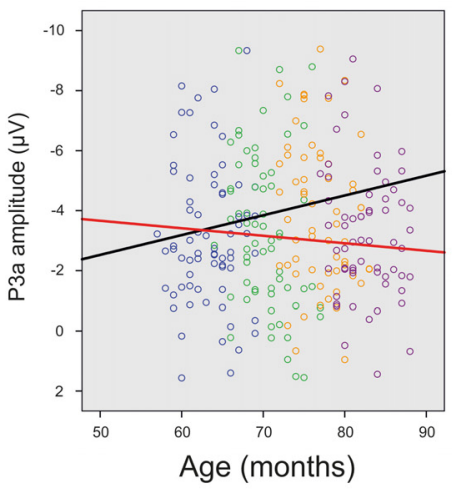

High mother's education

Low mother's education
B

\section{Consonant}

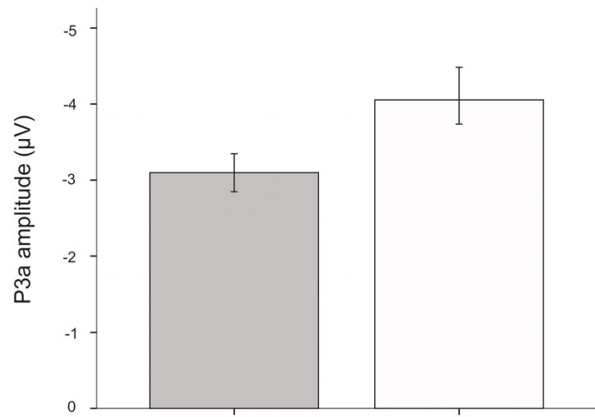

High mother's education

Low mother's education

- 1st measurement $\circ$ 2nd measurement

- 3rd measurement $\circ$ 4th measurement

FIGURE 4 | Significant interaction and marginally significant main effect for P3a response. The cut-off points for mother's education in figures are for illustration purposes only. (A) Individual P3a amplitudes for consonant deviants for all four measurements. Red line represents change in amplitudes for an individual with high (6/7) and black line for low (2/7) maternal education. (B) P3a amplitudes for consonant deviant averaged over all measurements for children with high (6/7) or low (2/7) maternal education (High: mean amplitude $-3.10 \mu \mathrm{V}, \mathrm{SEM}= \pm 0.28$, Low: mean amplitude $-4.06 \mu \mathrm{V}, \mathrm{SEM} \pm 0.40$ ).

\section{LDN}

A

\section{Intensity}

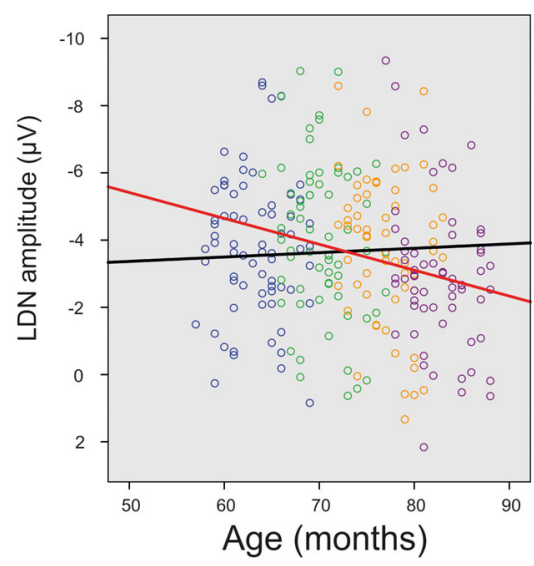

High mother's education
B

\section{Vowel}

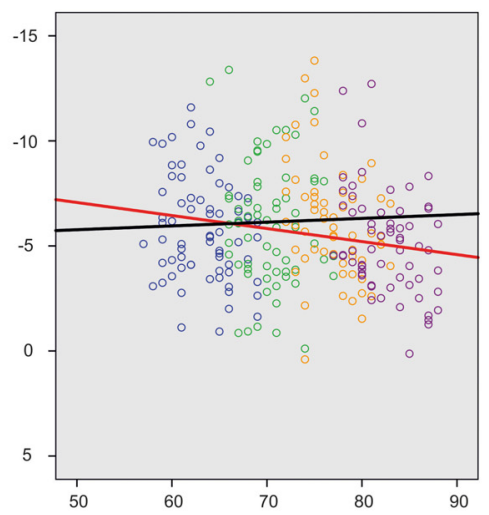

\section{Low mother's education}

$\circ 1$ st measurement $\circ$ 2nd measurement $\circ$ 3rd measurement $\circ 4$ th measurement

FIGURE 5 | Significant and marginally significant interactions for LDN response. The cut-off points for mother's education in figures are for illustration purposes only. The red line represents change in amplitudes for an individual with high (6/7) and the black line for an individual with low (2/7) maternal education. (A) Individual LDN amplitudes for intensity deviant for all four measurements. (B) Individual LDN amplitudes for vowel deviant for all four measurements. 
The P3a elicited by the vowel duration deviant did not change with age, and judging by the shape, the response to this deviant seems to be very solid early on. Apparently, duration change being very salient even for pre-schoolers might be due to Finnish being a quantity language and children learning to differentiate words based on the duration of phonemes (both vowel and consonant lengths) already at the early stage of life. Larger MMN responses of Finnish speakers to phoneme duration have been shown in adults (Ylinen et al., 2005; Tervaniemi et al., 2006) and are likely to occur already in childhood. Another possible explanation is that - unlike changes in phonemes processing duration does not require analysis of any subtle changes in sound features but simply noticing whether there is an ongoing sound or not. Still, whereas adults in similar paradigm (Pakarinen et al., 2009) showed a positive peak around $300 \mathrm{~ms}$ from sound onset, the detected deviation in duration does not seem to be large enough to elicit a positive P3a response already in 5-6-year-old children. Thus, the orienting of attention - while clearly more salient for duration change than for other deviants - will continue to develop later in childhood or adolescence.

While the main effect of age was not significant for the P3a responses for consonant deviant, there was a significant interaction of age and mother's education and a marginally significant main effect of mother's education for this response. These results suggest that the higher-SES children's P3a responses mature slightly faster than those of their lower-SES peers for consonant deviant during the inspected 20 months. Interestingly, based on the estimated slopes visualized in Figure 4A, it seems that the responses of children with lower-SES do not approach the positive values but show the opposite trajectory and grow more negative with age. This result is difficult to interpret but could be due to many ongoing processes of ERP maturation or differences in component latencies between low-SES and highSES children. Some previous studies (Gumenyuk et al., 2004; Wetzel et al., 2006) have found larger P3a responses in younger compared to older children, but our results do not support these findings. Naturally, it could be that the neural orienting of attention is going through different phases - P3a response increasing and decreasing - before auditory discrimination system is complete.

\section{LDN}

The LDN responses decreased significantly with age for the intensity deviant and marginally for the vowel deviant. Furthermore, the LDN amplitude for intensity deviant and marginally also for vowel deviant decreased with age more in children with higher maternal education. These results are in line with previous studies (Gumenyuk et al., 2004; Hommet et al., 2009; Bishop et al., 2011) showing smaller LDN amplitudes for older children, and further suggest that higher SES is connected with faster maturation of LDN responses. However, we did not find any support for the suggestion that LDN is related specifically to language processing (Korpilahti et al., 1996, 2001; Bishop et al., 2011; Kuuluvainen et al., 2016). Of course, this interpretation is questionable since all the stimuli were basically linguistic. Nevertheless, as the frequency and the intensity changes do not convey any linguistic meaning in Finnish language (except emotional connotations of the speaker), one would assume that the maturation of LDN responses would prove different for vowel, vowel duration and consonant changes compared to these, if the response was merely related to linguistic functions.

\section{CONCLUSION}

The variation in children's individual responses is large, and a lot of information is lost in averaging responses over fixed time window. Nevertheless, based on our study it seems clear that the auditory event-related potentials reflect changes in the processing of speech sounds between 5 and 6 years of age, showing enhancement and gaining of accuracy for several speech sound features. In connection with some speech-sound features, higher SES appears to boost this maturation. However, SES does not seem to have a profound effect on the maturation of these responses, which could be explained in our study by our sample of kindergarten children. Irrespective of the location, Finnish municipal kindergartens are of similar high quality with teachers having an academic degree. Furthermore, the kindergartens are low-cost (free for low-SES families), which allows children from different socio-economic backgrounds to benefit from early childhood education.

In future studies, the contribution of the teaching of letter symbols in pre-school (starting properly at the age of six in Finland) on the development of the neural speech-sound discrimination needs to be investigated. Furthermore, taking into account our recent findings about the correspondence between individual linguistic skills and MMN attributes in pre-school children (Linnavalli et al., 2017), in future one might be able to investigate a child's linguistic development with event-related potentials and thus identify the individuals benefiting from interventions enhancing language skills or auditory attention.

\section{DATA AVAILABILITY}

The pre-processed and epoched EEG data supporting the conclusions of this manuscript will be made available on reasonable request addressed to the authors, without undue reservation, to any qualified researcher.

\section{ETHICS STATEMENT}

This study was carried out in accordance with the Declaration of Helsinki and The Review Board of the Humanities and Social and Behavioral sciences in the University of Helsinki. We obtained written informed consent from the guardians of all subjects and verbal assent from the children participating in the experiments. The protocol was approved by The Review Board of the Humanities and Social and Behavioral sciences in the University of Helsinki, Finland. 


\section{AUTHOR CONTRIBUTIONS}

TL, MT, and MH designed the experiments. TL collected the data. TL and VP conducted the analyses. TL, VP, MH, and MT wrote the paper.

\section{ACKNOWLEDGMENTS}

This work was supported by graduate school of Humanities and Social Sciences (University of Helsinki) and Finnish Cultural Foundation. The authors would like to thank Tommi Makkonen, Jari Lipsanen, and Paavo Alku for helping with technical issues

\section{REFERENCES}

Alho, K., Sainio, K., Sajaniemi, N., Reinikainen, K., and Näätänen, R. (1990). Eventrelated brain potentials of human newborns to pitch change of an acoustic stimulus. Electroencephalogr. Clin. Neurophysiol. 77, 151-155. doi: 10.1016/ 0168-5597(90)90031-8

Alku, P., Tiitinen, H., and Näätänen, R. (1999). A method for generating naturalsounding speech stimuli for cognitive brain research. Clin. Neurophysiol. 110, 1329-1333. doi: 10.1016/S1388-2457(99)00088-7

Berti, S., Roeber, U., and Schröger, E. (2004). Bottom-up influences on working memory: behavioral and electrophysiological distraction varies with distractor strength. Exp. Psychol. 51, 249-257. doi: 10.1027/1618-3169.51. 4.249

Bishop, D. V. M., Hardiman, M. J., and Barry, J. G. (2011). Is auditory discrimination mature by middle childhood? A study using time-frequency analysis of mismatch responses from 7 years to adulthood. Dev. Sci. 14, 402-416. doi: 10.1111/j.1467-7687.2010.00990.x

Ceponiene, R., Lepistö, T., Soininen, M., Aronen, E., Alku, P., and Näätänen, R. (2003). Event-related potential indices of auditory vowel processing in 3-yearold children. Clin. Neurophysiol. 114, 652-661. doi: 10.1016/S1388-2457(02) 00436- 4

Cheour, M., Korpilahti, P., Martynova, O., and Lang, A.-H. (2001). Mismatch negativity and late discriminative negativity in investigating speech perception and learning in children and infants. Audiol. Neurootol. 6, 2-11. doi: 10.1159/ 000046804

Cheour, M., Leppänen, P., and Kraus, N. (2000). Mismatch negativity (MMN) as a tool for investigating auditory discrimination and sensory memory in infants and children. Clin. Neurophysiol. 111, 4-16. doi: 10.1016/S1388-2457(99) 00191-1

Csépe, V. (1995). On the origin and development of the mismatch negativity. Ear Hear. 16, 90-104. doi: 10.2307/1413001

Čeponienè, R., Cheour, M., and Näätänen, R. (1998). Interstimulus interval and auditory event-related potentials in children: evidence for multiple generators. Electroencephalogr. Clin. Neurophysiol. 108, 345-354. doi: 10.1016/S01685597(97)00081-6

Čeponienè, R., Lepistö, T., Soininen, M., Aronen, E., Alku, P., and Näätänen, R. (2004). Event-related potentials associated with sound discrimination versus novelty detection in children. Psychophysiology 42, 130-141. doi: 10.1111/j. 1469-8986.2003.00138.x

Čeponienè, R., Yaguchi, K., Shestakova, A., Alku, P., Suominen, K., and Näätänen, R. (2002). Sound complexity and 'speechness' effects on pre-attentive auditory discrimination in children. Int. J. Psychophysiol. 43, 199-211. doi: 10.1016/S0167-8760(01)00172-6

Datta, H., Shafer, V., Morr, M., Kurtzberg, D., and Schwartz, R. (2010). Electrophysiological indices of discrimination of long-duration, phonetically similar vowels in children with typical and atypical language development. J. Speech Lang. Hear. Res. 53, 757-777. doi: 10.1044/1092-4388(2009/080123)

Ervast, L., Hämäläinen, J. A., Zachau, S., Lohvansuu, K., Heinänen, K., Veijola, M., et al. (2015). Event-related brain potentials to change in the and Tuisku Tammi, Hanna Ylätalo and Henri Pitkänen for their assistance in data collection and handling. We gratefully acknowledge the help of the numerous kindergartens, their friendly personnel and the families participating in the research. Without their enthusiasm and support this study would not have been possible.

\section{SUPPLEMENTARY MATERIAL}

The Supplementary Material for this article can be found online at: https://www.frontiersin.org/articles/10.3389/fnins. 2018.00814/full\#supplementary-material

frequency and temporal structure of sounds in typically developing 5-6-yearold children. Int. J. Psychophysiol. 98, 413-425. doi: 10.1016/j.ijpsycho.2015. 08.007

Escera, C., Alho, K., Winkler, I., and Näätänen, R. (1998). Neural mechanisms of involuntary attention to acoustic novelty and change. J. Cogn. Neurosci. 10, 590-604. doi: 10.1162/089892998562997

Friedman, D., Cycowicz, Y. M., and Gaeta, H. (2001). The novelty P3: an event-related brain potential (ERP) sign of the brain's evaluation of novelty. Neurosci. Biobehav. Res. 25, 355-373. doi: 10.1016/S0149-7634(01)00 019-7

Gomot, M., Giard, M.-H., Roux, S., Barthélémy, C., and Bruneau, N. (2000). Maturation of frontal and temporal components of mismatch negativity (MMN) in children. Neuroreport 11, 3109-3112. doi: 10.1097/00001756200009280-00014

Gumenyuk, V., Korzyukov, O., Alho, K., Escera, C., and Näätänen, R. (2004). Effects of auditory distraction on electrophysiological brain activity and performance in children aged 8-13 years. Psychophysiology 41, 30-36. doi: $10.1111 / 1469-8986.00123$

Gumenyuk, V., Korzyukov, O., Alho, K., Winkler, I., Paavilainen, P., and Näätänen, R. (2003). Electric brain responses indicate preattentive processing of abstract acoustic regularities in children. Neuroreport 14, 1411-1415. doi: 10.1097/00001756-200308060-00001

Háden, G. P., Stefanics, G., Vestergaard, M. D., Denham, S. L., Sziller, I., and Winkler, I. (2009). Timbre-independent extraction of pitch in newborn infants. Psychophysiology 46, 69-74. doi: 10.1111/j.1469-8986.2008. 00749.x

Hommet, C., Vidal, J., Roux, S., Blanc, R., Barthez, M. A., De Becque, B., et al. (2009). Topography of syllable change-detection electrophysiological indices in children and adults with reading disabilities. Neuropsychologia 47, 761-770. doi: 10.1016/j.neuropsychologia.2008.12.010

Hong, T., Shuai, L., Frost, S. J., Landi, N., Pugh, K. R., and Shu, H. (2018). Cortical responses to Chinese phonemes in preschoolers predict their literacy skills at school age. Dev. Neuropsychol. 43, 356-369. doi: 10.1080/87565641.2018. 1439946

Huotilainen, M., Kujala, A., Hotakainen, M., Parkkonen, L., Taulu, S., Simola, J., et al. (2005). Short-term memory functions of the human fetus recorded with magnetoencephalography. Neuroreport 16, 81-84. doi: 10.1097/00001756200501190-00019

Kihara, M., Hogan, A. M., Newton, C. R., Garrashi, H. H., Neville, B. R., and de Haan, M. (2010). Auditory and visual novelty processing in normallydeveloping Kenyan children. Clin. Neurophysiol. 121, 564-576. doi: 10.1016/j. clinph.2009.11.086

Korpilahti, P., Krause, C., Holopainen, I., and Lang, H. (2001). Early and late mismatch negativity elicited by words and speech-like stimuli in children. Brain Lang. 76, 332-339. doi: 10.1006/brln.2000.2426

Korpilahti, P., Krause, C. M., and Lang, A. H. (ed.) (1996). "Automatic auditory word perception in children: Part I, event-related potentials (ERPs)," in Electrophysiological Correlates of Auditory Perception in Normal and Language Impaired Children, (Turku: University of Turku). 
Korpilahti, P., Lang, H., and Aaltonen, O. (1995). Is there a late latency mismatch negativity (MMN) component? Electroencephalogr. Clin. Neurophysiol. 95:96. doi: 10.1016/0013-4694(95)90016-G

Kostilainen, K., Wikström, V., Pakarinen, S., Videman, M., Karlsson, L., Keskinen, M., et al. (2018). Healthy full-term infants' brain responses to emotionally and linguistically relevant sounds using a multi-feature mismatch negativity (MMN) paradigm. Neurosci. Lett. 670, 110-115. doi: 10.1016/j.neulet. 2018.01.039

Kraus, N., Koch, D., McGee, T., Nicol, T., and Cunningham, J. (1999). Speech-sound discrimination in school-age children: psychophysical and neurophysiologic measures. J. Speech Lang. Hear. Res. 42, 1042-1060. doi: 10. 1044/jslhr.4205.1042

Kujala, T., Lovio, R., Lepistö, T., Laasonen, M., and Näätänen, R. (2006). Evaluation of multi-attribute auditory discrimination in dyslexia with the mismatch negativity. Clin. Neurophysiol. 117, 885-893. doi: 10.1016/j.clinph.2006. 01.002

Kushnerenko, E., Ceponiene, R., Balan, P., Fellman, V., Huotilainen, M., and Näätänen, R. (2002a). Maturation of the auditory event-related potentials during the first year of life. Neuroreport 13, 47-51. doi: 10.1097/00001756200201210-00014

Kushnerenko, E., Čeponienè, R., Balan, P., Fellman, V., and Näätänen, R. (2002b). Maturation of the auditory change detection response in infants: a longitudinal ERP study. Neuroreport 13, 1843-1848. doi: 10.1097/00001756-20021028000002

Kushnerenko, E., Winkler, I., Horváth, J., Näätänen, R., Pavlov, I., Fellman, V., et al. (2007). Processing acoustic change and novelty in newborn infants. Eur. J. Neurosci. 26, 265-274. doi: 10.1111/j.1460-9568.2007. 05628.x

Kuuluvainen, S., Alku, P., Makkonen, T., Lipsanen, J., and Kujala, T. (2016). Cortical speech and non-speech discrimination in relation to cognitive measures in preschool children. Eur. J. Neurosci. 43, 738-750. doi: 10.1111/ejn. 13141

Lee, C.-Y., Yen, H., Yeh, P., Lin, W.-H., Cheng, Y.-Y., Tzeng, Y.-L., et al. (2012). Mismatch responses to lexical tone, initial consonant, and vowel in Mandarin-speaking preschoolers. Neuropsychologia 50, 3228-3239. doi: 10. 1016/j.neuropsychologia.2012.08.025

Linnavalli, T., Putkinen, V., Huotilainen, M., and Tervaniemi, M. (2017). Phoneme processing skills are reflected in children's MMN responses. Neuropsychologia 101, 76-84. doi: 10.1016/j.neuropsychologia.20 17.05.0

Linnavalli, T., Putkinen, V., Lipsanen, J., Huotilainen, M., and Tervaniemi, M. (2018). Music playschool enhances children's linguistic skills. Sci. Rep. 8:8767. doi: 10.1038/s41598-018-27126-5

Lipina, S. J., and Posner, M. I. (2012). The impact of poverty on the development of brain networks. Front. Hum. Neurosci. 6:238. doi: 10.3389/fnhum.2012.00238

Liu, H.-M., Chen, Y., and Tsao, F.-M. (2014). Developmental changes in mismatch responses to Mandarin consonants and lexical tones from early to middle childhood. PLoS One 9:e95587. doi: 10.1371/journal.pone. 0095587

Lovio, R., Näätänen, R., and Kujala, T. (2010). Abnormal pattern of cortical speech feature discrimination in 6-year-old children at risk for dyslexia. Brain Res. 1335, 53-62. doi: 10.1016/j.brainres.2010.03.097

Lovio, R., Pakarinen, S., Huotilainen, M., Alku, P., Silvennoinen, S., Näätänen, R., et al. (2009). Auditory discrimination profiles of speech sound changes in 6year-old children as determined with the multi-feature MMN paradigm. Clin. Neurophysiol. 120, 916-921. doi: 10.1016/j.clinph.2009.03.010

Maurer, U., Bucher, K., Brem, S., and Brandeis, D. (2003). Development of the automatic mismatch response: from frontal positivity in kindergarten children to the mismatch negativity. Clin. Neurophysiol. 114, 808-817. doi: 10.1016/ S1388-2457(03)00032-4

Näätänen, R. (1992). Attention and Brain Function. Hillsdale, NJ: Erlbaum.

Näätänen, R., Astikainen, P., Ruusuvirta, T., and Huotilainen, M. (2010). Automatic auditory intelligence: an expression of the sensory-cognitive core of cognitive processes. Brain Res. Rev. 64, 123-136. doi: 10.1016/j.brainresrev. 2010.03.001

Näätänen, R., and Escera, C. (2000). Mismatch negativity: clinical and other applications. Audiol. Neurootol. 5, 105-110. doi: 10.1159/0000 13874
Näätänen, R., Paavilainen, P., Rinne, T., and Alho, K. (2007). The mismatch negativity (MMN) in basic research of central auditory processing: a review. Clin. Neurophysiol. 118, 2544-2590. doi: 10.1016/j.clinph.2007. 04.026

Näätänen, R., Pakarinen, S., Rinne, T., and Takegata, R. (2004). The mismatch negativity (MMN): towards the optimal paradigm. Clin. Neurophysiol. 115, 140-144. doi: 10.1016/j.clinph.2003.04.001

Pakarinen, S., Lovio, R., Huotilainen, M., Alku, P., Näätänen, R., and Kujala, T. (2009). Fast multi-feature paradigm for recording several mismatch negativities (MMNs) to phonetic and acoustic changes in speech sounds. Biol. Psychol. 82, 219-226. doi: 10.1016/j.biopsycho.2009.07.008

Partanen, E., Kujala, T., Tervaniemi, M., and Huotilainen, M. (2013a). Prenatal music exposure induces long-term neural effects. PLoS One 8:e78946. doi: 10. 1371/journal.pone.0078946

Partanen, E., Pakarinen, S., Kujala, T., and Huotilainen, M. (2013b). Infants' brain responses for speech sound changes in fast multifeature MMN paradigm. Clin. Neurophysiol. 124, 1578-1585. doi: 10.1016/j.clinph.2013. 02.014

Partanen, E., Torppa, R., Pykäläinen, J., Kujala, T., and Huotilainen, M. (2013c). Children's brain responses to sound changes in pseudo words in a multifeature paradigm. Clin. Neurophysiol. 124, 1132-1138. doi: 10.1016/j.clinph.2012.12. 005

Polich, J. (2007). Updating P300: an integrative theory of P3a and P3b. Clin. Neurophysiol. 118, 2128-2148. doi: 10.1016/j.clinph.2007.04.019

Putkinen, V., Niinikuru, R., Lipsanen, J., Tervaniemi, M., and Huotilainen, M. (2012). Fast measurement of auditory event-related potential profiles in 2-3-year-olds. Dev. Neuropsychol. 37, 51-75. doi: 10.1080/87565641.2011.61 5873

Rinne, T., Alho, K., Ilmoniemi, R. J., Virtanen, J., and Näätänen, R. (2000). Separate time behaviors of the temporal and frontal mismatch negativity sources. Neuroimage 12, 14-19. doi: 10.1006/nimg.2000.0591

Ruhnau, P., Herrmann, B., Maess, B., Brauer, J., Friederici, A., and Schröger, E. (2013). Processing of complex distracting sounds in school-aged children and adults: evidence from EEG and MEG data. Front. Psychol. 4:717. doi: 10.3389/ fpsyg.2013.00717

Ruhnau, P., Wetzel, N., Widmann, A., and Schröger, E. (2010). The modulation of auditory novelty processing by working memory load in school age children and adults: a combined behavioral and event-related potential study. BMC Neurosci. 11:126. doi: 10.1186/1471-2202-11-126

Shafer, V., Morr, M., Datta, H., Kurtzberg, D., and Schwartz, R. (2005). Neurophysiological indexes of speech processing deficits in children with specific language impairment. J. Cogn. Neurosci. 17, 1168-1180. doi: 10.1162/ 0898929054475217

Shafer, V., Morr, M., Kreuzer, J., and Kurtzberg, D. (2000). Maturation of mismatch negativity in school-age children. Ear Hear. 21, 242-251. doi: 10 1097/00003446-200006000-00008

Shafer, V. L., Yu, Y. H., and Datta, H. (2010). Maturation of speech discrimination in 4- to 7-yr-old children as indexed by event-related potential mismatch responses. Ear Hear. 31, 735-745. doi: 10.1097/AUD.0b013e3181e $5 \mathrm{~d} 1 \mathrm{a} 7$

Tervaniemi, M., Jacobsen, T., Röttger, S., Kujala, T., Widmann, A., Vainio, M., et al. (2006). Selective tuning of cortical sound-feature processing by language experience. Eur. J. Neurosci. 23, 2538-2541. doi: 10.1111/j.1460-9568.2006. 04752.x

Tomalski, P., Moore, D. G., Ribeiro, H., Axelsson, E. L., Murphy, E., KarmiloffSmith, A., et al. (2013). Socioeconomic status and functional brain development - associations in early infancy. Dev. Sci. 16, 676-687. doi: 10.1111/desc.12079 doi: 10.1111/desc. 12079

Trainor, L., Samuel, S., Desjardins, R., and Sonnadara, R. (2001). Measuring temporal resolution in infants using mismatch negativity. Neuroreport 12 , 2443-2448. doi: 10.1097/00001756-200108080-00031

West, B. (2009). Analyzing longitudinal data with the linear mixed models procedure in SPSS. Eval. Health Prof. 32, 207-228. doi: $10.1177 / 0163278709338554$

Wetzel, N., Widmann, A., Berti, S., and Schröger, E. (2006). The development of involuntary and voluntary attention from childhood to adulthood: a combined behavioral and event-related potential study. Clin. Neurophysiol. 117, 2191-2203. doi: 10.1016/j.clinph.2006.06.717 
Winkler, I., Denham, S. L., and Nelken, I. (2009). Modeling the auditory scene: predictive regularity representations and perceptual objects. Trends Cogn. Sci. 13, 532-540. doi: 10.1016/j.tics.2009.09.003

Yago, E., Corral, M. J., and Escera, C. (2001). Activation of brain mechanisms of attention switching as a function of auditory frequency change. Neuroreport 12, 4093-4097. doi: 10.1097/00001756-20011221000046

Ylinen, S., Shestakova, A., Alku, P., and Huotilainen, M. (2005). The perception of phonological quantity based on durational cues by native speakers, secondlanguage users and nonspeakers of Finnish. Lang. Speech 48, 313-338. doi: $10.1177 / 00238309050480030401$
Conflict of Interest Statement: The authors declare that the research was conducted in the absence of any commercial or financial relationships that could be construed as a potential conflict of interest.

Copyright (c) 2018 Linnavalli, Putkinen, Huotilainen and Tervaniemi. This is an open-access article distributed under the terms of the Creative Commons Attribution License (CC BY). The use, distribution or reproduction in other forums is permitted, provided the original author(s) and the copyright owner(s) are credited and that the original publication in this journal is cited, in accordance with accepted academic practice. No use, distribution or reproduction is permitted which does not comply with these terms. 